J Adolesc Health. 2011 August ; 49(2): 206-212. doi:10.1016/j.jadohealth.2010.12.001.

\title{
Growing Up With a Chronic Illness: Social Success, Educational/ Vocational Distress
}

\author{
Gary R. Maslow, MD ${ }^{1,2}$, Abigail Haydon, MPH ${ }^{3,4}$, Annie-Laurie McRee, MPH $^{3}$, Carol Ann \\ Ford, $\mathbf{M D}^{3,5}$, and Carolyn Tucker Halpern, PhD $^{3,4}$ \\ ${ }^{1}$ Cecil B. Sheps Center for Health Services Research, University of North Carolina at Chapel Hill, \\ Chapel Hill, NC \\ 2Department of Pediatrics, Duke University Medical Center, Durham, NC \\ ${ }^{3}$ Department of Maternal and Child Health, UNC Gillings School of Global Health, Chapel Hill, NC \\ ${ }^{4}$ Carolina Population Center, The University of North Carolina at Chapel Hill, Chapel Hill, NC \\ ${ }^{5}$ Department of Pediatrics, UNC School of Medicine, Chapel Hill, NC
}

\begin{abstract}
OBJECTIVES-We compared adult educational, vocational, and social outcomes among young adults with and without childhood-onset chronic illness in a nationally representative US sample.

METHODS-We used data from Wave IV (2008) of the National Longitudinal Study of Adolescent Health. We compared respondents who reported childhood onset cancer, heart disease, diabetes, or epilepsy to young adults without these chronic illnesses in terms of marriage, having children, living with parents, romantic relationship quality, educational attainment, income and employment. Multivariate models controlled for socio-demographic factors and adult-onset chronic illness.
\end{abstract}

RESULTS-Compared to those without childhood chronic illness, respondents with childhood chronic illness had similar odds of marriage ( $\mathrm{OR}=0.89,95 \% \mathrm{CI}$ : $0.65-1.24)$, having children $(\mathrm{OR}=0.99,95 \% \mathrm{CI}: 0.70-1.42)$, and living with parents $(\mathrm{OR}=1.49,95 \% \mathrm{CI} 0.94-2.33)$, and similar reports of romantic relationship quality. However, the chronic illness group had lower odds of graduating college (OR=0.49, 95\%CI: $0.31-0.78)$ and being employed (OR $=0.56,95 \% \mathrm{CI}: 0.39$ 0.80 ), and higher odds of receiving public assistance ( $\mathrm{OR}=2.13,95 \% \mathrm{CI}: 1.39-3.25)$, and lower mean income.

CONCLUSIONS-Young adults growing up with chronic illness succeed socially, but are at increased risk of poorer educational and vocational outcomes.

\section{Introduction}

Over the past 40 years, advances in pediatric medicine decreased the mortality rate of many once uniformly fatal chronic diseases. Medical success resulted in children who would have died early in life living to be adults. For example, life expectancy for a child born with sickle

\footnotetext{
(C) 2010 Society for Adolescent Medicine. Published by Elsevier Inc. All rights reserved.

Corresponding Author: Gary Maslow, MD, Cecil G. Sheps Center for Health Services Research, The University of North Carolina at Chapel Hill, 725 Martin Luther King Jr. Blvd., CB\# 7590, Chapel Hill, NC 27599, maslow@ unc.edu, Telephone: (401) 954-2789.

Publisher's Disclaimer: This is a PDF file of an unedited manuscript that has been accepted for publication. As a service to our customers we are providing this early version of the manuscript. The manuscript will undergo copyediting, typesetting, and review of the resulting proof before it is published in its final citable form. Please note that during the production process errors may be discovered which could affect the content, and all legal disclaimers that apply to the journal pertain.
} 
cell disease has increased from only 14 years in 1970 to a current estimate of over 40 years. ${ }^{1,2}$ This increase in life expectancy cuts across almost all childhood-onset diseases. It is estimated that over $90 \%$ of children born with a chronic condition will survive to 20 years old. ${ }^{3,4}$

With success in extending the lives of children with chronic conditions, new challenges emerge. Each year an estimated 500,000 children with special health care needs turn 18 . Many physicians and parents express concern that they will experience poor educational, vocational, and social outcomes as adults. ${ }^{5}$ Such concerns may be warranted, as crosssectional data from European samples indicate that young adults with a variety of childhoodonset chronic conditions have lower educational attainment and employment rates, and experience social deficits ranging from lower rates of marriage to higher rates of parental divorce compared to control groups. ${ }^{6-9}$

Data from longitudinal studies of adolescents with chronic illness followed into adulthood reveal a more mixed picture. In a 1946 British birth cohort followed through 1982, those with childhood-onset chronic illness had higher rates of unemployment and lower rates of marriage at age 36, but had similar educational attainment. ${ }^{10,11}$ In another study of an adolescent cohort from one Finnish town the chronic illness group did not differ from the healthy peer comparison group, except for a lower marriage rate. ${ }^{12,13}$ Findings based on a U.S. sample were also mixed; an analysis of data from the National Longitudinal Survey of Youth 1979 indicated that, compared to healthy peers, those with chronic illness (either childhood or early adult-onset) had the same educational and marital outcomes but lower rates of employment and lower annual personal income (approximately $\$ 1,700$ less when participants were 21 to 28 years old). ${ }^{14}$

The same mixed picture regarding adult outcomes found in non-categorical studies - which group together individuals with a variety of chronic childhood illnesses, based on evidence that many of the consequences of childhood-onset chronic illness are similar across conditions ${ }^{15,16}$ - is also apparent in longitudinal studies examining specific conditions. For example, a longitudinal US study comparing the adult outcomes of cancer survivors and their siblings and showed that cancer survivors had lower educational attainment and employment rates, lower income, and lower rates of marriage, particularly for those with central nervous system tumors or treatment. ${ }^{17-22}$ With respect to epilepsy, data from Japan indicate comparable educational, vocational, and social outcomes for those with normal intelligence, but worse outcomes for those with mental retardation. ${ }^{23}$ In contrast, Finnish and Canadian studies indicate worse outcomes across all domains. ${ }^{24}$ Overall, young adults with childhood-onset chronic illness appear to be at risk of worse educational and vocational outcomes regardless of the specific condition, and certain factors such as central nervous system disease may put individuals at greater risk.

Current research on the adult experiences of those with childhood-onset illness has a number of key limitations. First, medical advances have progressed so dramatically that data from earlier birth cohorts may not be applicable to children being treated for chronic illnesses today. A second, related limitation is the difficulty in generalizing current findings to children across the United States with a variety of chronic conditions because most studies are from other countries or are not representative of the modern US population. Finally, although most studies on childhood chronic illness take a non-categorical approach, examining the generic effects of a range of chronic illness on psychosocial outcomes, many include mild conditions such as seasonal allergies or mild asthma that may not have the same effects as more severe conditions. Studies that include milder conditions may attenuate the detected effects of chronic illness on adult outcomes. ${ }^{15,16}$ 
The present study examines educational, vocational and social outcomes of young adults with childhood-onset chronic illness using nationally-representative data from the National Longitudinal Study of Adolescent Health (Add Health). We hypothesize that young adults with childhood-onset chronic illness will have worse educational, vocational, and social outcomes than young adults without childhood-onset chronic illness. A secondary aim is to examine the outcomes of young adults with adult-onset chronic illness compared with those without chronic illness and those with childhood-onset chronic illness to determine if timing of onset has implications for outcomes examined.

\section{Methods}

\section{Data}

Data comes from Waves I and IV of Add Health. Add Health is a nationally representative sample of U.S. adolescents enrolled in grades seven through twelve in the 1994-1995 school year (Wave I). Add Health sampling procedures and study design are described in detail elsewhere ${ }^{25}$ Our analytic sample consisted of respondents who participated in Wave I (1994-1995) and Wave IV (2008) in-home interviews ( $\mathrm{n}=15,701)$, had valid sample weights, and had complete data on primary outcomes of interest $(n=13,965)$. The Public Health-Nursing Institutional Review Board at the University of North Carolina at Chapel Hill approved the Add Health study.

\section{Measures}

Chronic Illness-We identified respondents with a chronic illness based on Wave IV selfreport of ever having been diagnosed with cancer, diabetes, epilepsy, or heart disease; respondents also reported age of diagnosis. Although the survey included questions about asthma, there were no questions to assess severity. Given prior research indicating that young adults with asthma of uncertain severity have similar outcomes as young adults without chronic illness, ${ }^{26}$ we did not include those with asthma in the chronic illness group. No other childhood chronic illnesses or conditions were included in the questionnaire. For purposes of the present analysis, we categorized respondents as having childhood-onset chronic illness ( $\leq 18$ years), adult-onset chronic illness ( $>18$ years old), or no chronic illness (referent category).

Young adult outcomes-Using data from Wave IV, we assessed multiple educational, vocational, economic and social outcomes during young adulthood (ages 24-32 years).

Educational attainment was defined as the highest level of education respondents had attained (less than high school education, high school graduate or graduate equivalency diploma, some college, and college graduate or higher). For select analyses college graduation was also coded as a dichotomous variable ( $1=$ graduated from college, $0=\mathrm{did}$ not graduate from college).

Vocational outcomes included two dichotomous variables: Ever had a full or part-time job $(1=y e s, 0=$ no $)$ and currently employed at a full or part-time job $(1=y e s, 0=$ no).

Economic outcomes were assessed using two measures. Receipt of public assistance indicated that a member of the respondent's household had received some form of public assistance since the last interview, 6 years earlier. Respondent's individual income was reported on a continuous scale. Individual income was missing for 657 respondents; these respondents were excluded from the income analysis $(\mathrm{N}=13,308)$. Because individual income was significantly skewed, with many respondents reporting no income, we chose to also examine income percentile. 
Social outcomes included living situation, marital history, and having children. Living situation was assessed based on a household roster by grouping respondents who currently lived with a parent versus those who lived in other living situations. Marital history (ever been married) and having a biological child were each treated as dichotomous outcomes.

Quality of each respondents' primary romantic relationship was assessed using a 7 item scale derived from the Strengthening Healthy Marriage baseline instrument. ${ }^{27}$ The analytic sample for the romantic relationship quality scale consisted of all respondents in the analytic sample who reported at least one past or present romantic relationship (married, cohabiting, or dating) and for whom complete data were available for the romantic relationship quality scale $(\mathrm{N}=13,388)$. After providing a relationship history, respondents were asked a series of detailed questions about their current relationship and partner. Those respondents who were not in a current relationship were asked about a relationship with a past partner, using the following priority sequence: most recent marriage partner, most recent cohabitation partner (defined as a partner with whom the respondent lived but never married), most recent pregnancy partner (defined as a partner with whom the respondent had a pregnancy but never lived with and never married), and most recent dating partner (defined as a partner with whom the respondent had a romantic relationship but never married, cohabited with, or had a pregnancy with).

To assess relationship quality, respondents were asked to indicate how much they agreed or disagreed with 7 statements using a 5 point Likert scale (1=strongly disagree, $5=$ strongly agree). The items included:

1. We (enjoy/enjoyed) doing even ordinary, day-to-day things together;

2. I (am/was) satisfied with the way we handle our problems and disagreements;

3. I (am/was) satisfied with the way we handle family finances;

4. My partner (listens/listened) to me when I need someone to talk to;

5. My partner (expresses/expressed) love and affection to me;

6. I (am/was) satisfied with our sex life;

7. I (trust/trusted) my partner to be faithful to me.

Items were reversed coded so a higher mean score indicated higher relationship quality $(a=0.89)$. For analysis, we created dummy variables for each relationship type: marriage partner, cohabitation partner, pregnancy partner, and dating partner. Because past relationships may be more likely to be rated of lower quality, we also controlled for whether the relationship was current.

Control variables-Our analyses controlled for factors that could independently contribute to young adult outcomes. Age at Wave IV was a continuous variable. Sex was coded as female or male (referent category). Socioeconomic status of family of origin was based on highest level of education for either parent as reported by the adolescent respondent at Wave I (less than high school, high school graduate, some college, college graduate, and schooling beyond college, with less than high school as the referent). Race/ ethnicity was based on Wave I self-report and classified into non-Hispanic white (referent), non-Hispanic black, Hispanic, and other race/ethnicity.

In addition to the controls described above, models predicting income also adjusted for educational attainment, current employment, and being in school currently. We categorized respondents' current employment as not having a job, having a part-time job, or having a full-time job. 


\section{Data analysis}

We began by examining bivariate associations between outcome variables and illness status. Multivariate logistic regression was used to model dichotomous outcomes, controlling for sex, age, race/ethnicity, and parent education. Romantic relationship quality and income were examined using linear regression. We examined raw income and income percentiles using tobit regression (a type of regression that allows for censoring of skewed data) and linear regression with similar results. For ease of presentation and understanding, the adjusted means from the linear regression are reported. All analyses were conducted in Stata 11.0 statistical software (College Station, Tx). We adjusted for Add Health's complex survey design and used sample weights to generate national probability estimates.

\section{Results \\ Participants}

Sample characteristics are presented in Table 1. At Wave IV, respondents were between 24 and 32 years old with a mean age of 28.8 years $(\mathrm{SD}=0.1)$. Approximately $2 \%$ of respondents reported a childhood-onset chronic illness and 3\% reported adult-onset chronic illness. Most respondents with childhood onset chronic illness had epilepsy (44\%) or diabetes (24\%). Fewer reported diagnosis of heart disease (18\%) or cancer (16\%). For those with adult onset chronic illness, over half had diabetes (59\%); adult diagnosis of cancer (23\%), epilepsy $(12 \%)$, and heart disease (10\%) were less common. Childhood and adult-onset chronic illnesses were associated with lower parental education and female sex. There were no differences in age or race/ethnicity between the two chronic illness groups and the group without a chronic illness.

\section{Bivariate analyses}

Compared to the group without chronic illness (Table 1), young adults with childhood-onset chronic illness had lower rates of high school graduation ( $87.1 \%$ vs. $91.9 \%)$, college attendance (57.6\% vs. $71.9 \%)$, college graduation (18.0\% vs. $32.2 \%)$, ever having a job $(89.8 \%$ vs. $94.6 \%)$, and having a current job $(52.5 \%$ vs. $67.5 \%)$. Adults with childhoodonset chronic illness had higher rates of receiving public assistance ( $40.6 \%$ vs. $22.8 \%$ ).

In contrast, respondents with adult-onset chronic illness looked more similar to those without chronic illness. Compared to those without chronic illness, young adults with adultonset chronic illness had similar rates of ever having a job (93.3\% vs. $94.6 \%)$ and college attendance $(65.9 \%$ vs. $71.9 \%)$, but much lower rates of college graduation $(19.1 \%$ vs. $32.2 \%)$ and having a current job (58.6\% vs. $67.5 \%)$.

Young adults in each chronic illness group looked similar to adults without a chronic illness on the social outcomes examined, currently living with parents, ever being married, and having children. The type of relationship assessed via the romantic quality scale was different between the groups with the childhood-onset chronic illness group being less likely to report about a marital relationship. There was not a difference whether the relationship was current.

\section{Multivariate analyses}

Educational, Vocational, and Economic Outcomes-Results of the multivariate models are presented in Table 2 for dichotomous variables and in Table 3 for continuous variables. Adjusting for age, sex, race/ethnicity, and parent education, educational and vocational outcomes were significantly worse for the childhood-onset chronic illness group compared to those without a chronic illness. Those with childhood-onset chronic illness were less likely to be a college graduate $(\mathrm{OR}=0.49,95 \% \mathrm{CI}$ : $0.31,0.78)$; less likely to have 
ever had a job (OR= $0.53,95 \%$ CI: $0.29,0.97)$; less likely to have a current job $(\mathrm{OR}=0.56$, 95\% CI: 0.39,0.80); and more likely to have received public assistance (OR=2.13, 95\% CI: 1.39,3.25). The adjusted mean income for young adults with childhood-onset chronic illness was lower by $\$ 5,157$ (95\% CI: $-2336,-7977)$ than adjusted mean income for young adults without chronic illness, controlling for educational attainment, current employment status, and whether the respondent was currently a student (Table 3 ). In contrast, young adults with adult-onset chronic illness looked similar to young adults without chronic illness in terms of ever having a job and income, but were less likely to be a college graduate ( $\mathrm{OR}=0.60,95 \%$ CI: $0.38,0.72)$, less likely to have a current job (OR=0.56, 95\% CI: $0.56,0.93)$, and more likely to receive public assistance ( $\mathrm{OR}=0.56,95 \% \mathrm{CI}: 1.33,2.26)$ (Table 2).

\section{Social Outcomes}

Adjusting for controls, all groups were similar in their odds of living with parents, ever having been married, and having children of their own (Table 2). In addition, there was no difference in the quality of romantic relationships between groups, with the mean relationship quality score for each group approximately equal to 4.0 , indicating generally positive perceptions of romantic relationship quality (Table 3).

\section{Comparison between childhood-onset and adult-onset chronic illness groups}

The childhood-onset and adult-onset chronic illnesses groups were also compared to each other using multivariate models and there were no statistically significant differences in any outcomes (results not shown).

\section{Discussion}

In this nationally-representative sample, we found that the majority of young adults in the US with childhood-onset chronic illness do well educationally, vocationally, and socially. However, while young adults with childhood-onset chronic illness do not differ on the social outcomes examined, they do fare worse than young adults without chronic illness on educational, vocational, and income outcomes, with half the odds of graduating college and having a current a job, and substantially lower mean income. Differences in income persist after controlling for educational attainment and employment status. These findings are consistent with some earlier studies that examined educational and vocational outcomes of young adults with childhood-onset chronic illness, ${ }^{6,11,13,14}$ and likely reflect a variety of complex causal mechanisms, such as absenteeism from school or work and other factors that can affect the developmental trajectory of young adult vocational readiness and educational attainment. $^{28,} 29$

Adult onset of chronic illness appears be less strongly associated with the young adulthood outcomes we measured, possibly indicating distinct underlying mechanisms related to timing of onset. A greater proportion of young adults with adult-onset chronic illness start college than those whose illness was diagnosed during childhood or adolescence, but the groups have similar rates of college graduation. Perhaps the low college graduation rate for those with childhood-onset chronic illness primarily reflects a lower likelihood of attending college in the first place rather than barriers to completion. Future research examining the mechanisms contributing to the effect of timing of chronic illness on educational and vocational outcomes of young adults is warranted.

In contrast to our results regarding educational and vocational outcomes, young adults with childhood-onset chronic illness do not differ from those without a chronic illness on any of the examined social outcomes. To our knowledge, this study is the first to investigate the quality of romantic relationships in young adults with childhood chronic illness in a large 
national sample. As seen with other social indicators, there were no differences based on timing of chronic illness onset, with all groups reporting similarly high levels of romantic relationship quality. This finding is consistent with prior case-control studies which found that young adults with and without chronic illness reported similar quality of dating relationships, similar satisfaction with romantic relationships, and similar numbers of romantic relationships. ${ }^{30-32}$ However, in contrast to previous findings that young adults with chronic illness are less likely to marry, $6,11,13$ we find that chronic illness is not related to marriage. This difference could be related to this analysis being conducted on a U.S., as opposed to European, sample, or to our use of a nationally representative sample, as opposed to a clinic-based sample.

The mechanisms that lead to social success likely differ from those that promote educational and vocational success. While there is a concern among parents and health care providers that children with chronic illness are destined to face peer difficulties, most studies have found that they do not have increased social problems. ${ }^{39,} 40$ Peer interaction is an important and natural part of childhood, and for children with a chronic illness being around peers may promote adjustment to their illness. It is also possible that parents may focus on social aspects of a child's life and encourage social activities preferentially over school or other activities. The role of parents and others in promoting the social success of this group is important to investigate in future work. The developmental process by which an adolescent finds a job - and ultimately a career - is complex and influenced by family, prior work experience, and a variety of other contextual factors. ${ }^{29}$ More research is needed to determine the specific factors that lead to the educational and vocational differences faced by those with childhood-onset chronic illness.

The present study provides evidence that the effect of having a chronic physical illness (such as cancer, diabetes, epilepsy, and heart disease) on educational and vocational outcomes is similar to the effect of having a disability in childhood..$^{33}$ The educational and vocational needs of children growing up with a disability are addressed by federal policy and law, including the Individuals with Disability Act (IDEA). ${ }^{34}$ However, children with chronic illnesses may not qualify as having a disability under the IDEA and therefore may not have access to additional supports - which have been found to be effective at improving vocational outcomes ${ }^{33}$ - that are available to children with disability. ${ }^{35,} 36$ Allowing children with chronic illness to qualify for similar types of support, such as school reintegration following hospitalization, without having to meet the formal criteria for receiving an Individualized Education Plan (IEP) (a mechanism for increased educational support through IDEA) could improve their educational and vocational outcomes. ${ }^{37,} 38$

The present study has several limitations. The questionnaire did not include many relatively common childhood conditions, potentially misclassifying young adults with childhood-onset chronic illnesses (e.g., inflammatory bowel disease or sickle cell disease, among others) in the "no chronic illness" group. This misclassification may dilute the observed associations with chronic illness. Alternatively, poor educational and vocational outcomes may be attributable to factors specific to the four examined conditions. In addition, details regarding severity or precise timing of illness onset were not available. Further study is needed to replicate these findings in other populations with a more comprehensive range of childhoodonset chronic illness.

\section{Conclusion}

With advances in pediatric medicine continuing to extend the lives of children with previously fatal childhood-onset conditions there will be an increasing number of young adults with childhood-onset chronic illness. The surprising social success of young adults 
with childhood-onset chronic illness warrants further study, as this may reflect social services already provided in hospitals and clinics or other unknown support mechanisms. Although the majority of young adults with childhood-onset chronic illness are successful in terms of completing high school and having a current job, they are at disproportionate risk of poorer educational and vocational outcomes compared to young adults without a chronic illness. Less than a fifth of young adults with childhood-onset chronic illness graduate college and their mean income is significantly lower than those without chronic illness. This demonstrates a need to understand mechanisms underlying these differences and thereby inform the development of targeted interventions to support the educational and vocational development of individuals with childhood-onset chronic illness.

\section{Acknowledgments}

This research uses data from Add Health, a program project directed by Kathleen Mullan Harris and designed by J. Richard Udry, Peter S. Bearman, and Kathleen Mullan Harris at the University of North Carolina at Chapel Hill, and funded by grant P01-HD31921 from the Eunice Kennedy Shriver National Institute of Child Health and Human Development, with cooperative funding from 23 other federal agencies and foundations. Special acknowledgment is due Ronald R. Rindfuss and Barbara Entwisle for assistance in the original design. Information on how to obtain the Add Health data files is available on the Add Health website (http://www.cpc.unc.edu/addhealth). No direct support was received from grant P01-HD31921 for this analysis.

Training support for Gary Maslow, MD provided by T32HP14001 from the Health Resources and Services Administration for UNC's NRSA Primary Care Research Fellowship. Effort by A Haydon and CT Halpern was supported by NICHD grant R01-HD57046, CT Halpern, Principal Investigator. Thanks to the NRSA Primary Care Research Fellows for careful review of this manuscript.

\section{References}

1. Platt OS, Brambilla DJ, Rosse WF, et al. Mortality in sickle cell disease. Life expectancy and risk factors for early death. N Engl J Med. 1994 Jun 9; 330(23):1639-1644. [PubMed: 7993409]

2. Quinn CT, Rogers ZR, Buchanan GR. Survival of children with sickle cell disease. Blood. 2004 Jun 1; 103(11):4023-4027. [PubMed: 14764527]

3. Gortmaker SL, Sappenfield W. Chronic childhood disorders: prevalence and impact. Pediatr Clin North Am. 1984 Feb; 31(1):3-18. [PubMed: 6366717]

4. Pinzon J. Canadian Paediatric Society Statement: Care of Adolescents with Chronic Conditions. Paediatrics and Child Health. 2006; 11(1):43-48.

5. Reiss J, Gibson R. Health care transition: destinations unknown. Pediatrics. 2002 Dec; $110(6 \mathrm{Pt} 2)$ : 1307-1314. [PubMed: 12456950]

6. Kokkonen J. The social effects in adult life of chronic physical illness since childhood. Eur J Pediatr. 1995 Aug; 154(8):676-681. [PubMed: 7588973]

7. Stam H, Hartman EE, Deurloo JA, Groothoff J, Grootenhuis MA. Young adult patients with a history of pediatric disease: impact on course of life and transition into adulthood. J Adolesc Health. 2006 Jul; 39(1):4-13. [PubMed: 16781955]

8. Miauton L, Narring F, Michaud PA. Chronic illness, life style and emotional health in adolescence: results of a cross-sectional survey on the health of 15-20-year-olds in Switzerland. Eur J Pediatr. 2003 Oct; 162(10):682-689. [PubMed: 12915981]

9. Gledhill J, Rangel L, Garralda E. Surviving chronic physical illness: psychosocial outcome in adult life. Arch Dis Child. 2000 Aug; 83(2):104-110. [PubMed: 10906013]

10. Pless IB, Douglas JW. Chronic illness in childhood. I. Epidemiological and clinicl characteristics. Pediatrics. 1971 Feb; 47(2):405-414. [PubMed: 5100779]

11. Pless IB, Cripps HA, Davies JM, Wadsworth ME. Chronic physical illness in childhood: psychological and social effects in adolescence and adult life. Dev Med Child Neurol. 1989 Dec; 31(6):746-755. [PubMed: 2599268]

12. Bussing R, Aro H. Youth with chronic conditions and their transition to adulthood. Findings from a Finnish cohort study. Arch Pediatr Adolesc Med. 1996 Feb; 150(2):181-186. [PubMed: 8556123] 
13. Huurre TM, Aro HM. Long-term psychosocial effects of persistent chronic illness. A follow-up study of Finnish adolescents aged 16 to 32 years. Eur Child Adolesc Psychiatry. 2002 Apr; 11(2): 85-91. [PubMed: 12033749]

14. Gortmaker SL, Perrin JM, Weitzman M, Homer CJ, Sobol AM. An Unexpected Success Story: Transition to Adulthood in Youth with Chronic Physical Health Conditions. Journal of Research on Adolesence. 1993; 3(3):317-336.

15. Stein RE, Jessop DJ. A noncategorical approach to chronic childhood illness. Public Health Rep. 1982 Jul-Aug;97(4):354-362. [PubMed: 7111657]

16. Perrin EC, Newacheck P, Pless IB, et al. Issues involved in the definition and classification of chronic health conditions. Pediatrics. 1993 Apr; 91(4):787-793. [PubMed: 8464668]

17. Boman KK, Lindblad F, Hjern A. Long-term outcomes of childhood cancer survivors in Sweden: a population-based study of education, employment, and income. Cancer. Mar 1; 116(5):1385-1391. [PubMed: 20087961]

18. Ellenberg L, Liu Q, Gioia G, et al. Neurocognitive status in long-term survivors of childhood CNS malignancies: a report from the Childhood Cancer Survivor Study. Neuropsychology. 2009 Nov; 23(6):705-717. [PubMed: 19899829]

19. Mitby PA, Robison LL, Whitton JA, et al. Utilization of special education services and educational attainment among long-term survivors of childhood cancer: a report from the Childhood Cancer Survivor Study. Cancer. 2003 Feb 15; 97(4):1115-1126. [PubMed: 12569614]

20. Pang JW, Friedman DL, Whitton JA, et al. Employment status among adult survivors in the Childhood Cancer Survivor Study. Pediatr Blood Cancer. 2008 Jan; 50(1):104-110. [PubMed: 17554791]

21. Gurney JG, Krull KR, Kadan-Lottick N, et al. Social outcomes in the Childhood Cancer Survivor Study cohort. J Clin Oncol. 2009 May 10; 27(14):2390-2395. [PubMed: 19224833]

22. Lancashire ER, Frobisher C, Reulen RC, Winter DL, Glaser A, Hawkins MM. Educational attainment among adult survivors of childhood cancer in Great Britain: a population-based cohort study. J Natl Cancer Inst. Feb 24; 102(4):254-270. [PubMed: 20107164]

23. Wakamoto H, Nagao H, Hayashi M, Morimoto T. Long-term medical, educational, and social prognoses of childhood-onset epilepsy: a population-based study in a rural district of Japan. Brain Dev. 2000 Jun; 22(4):246-255. [PubMed: 10838113]

24. Camfield CS, Camfield PR. Long-term social outcomes for children with epilepsy. Epilepsia. 2007; 48(Suppl 9):3-5. [PubMed: 18047590]

25. Harris, KM.; Halpern, CT.; Whitsel, E., et al. The National Longitudinal Study of Adolescent Health: Research Design. 2009. http://www.cpc.unc.edu/projects/addhealth/design.

26. Maslow G, Hayden A, Ford C, Halper C. Young Adult Outcomes of Children Growing up with Chronic Illness: An analysis of the National Longitudinal Study of Adolescent Health. 2010 Manuscript under review.

27. Guzman, L.; Moore, K.; Matthews, G.; Redd, Z. Summary Report on Cognitive Interviews for Healthy Marriage Item Development. For Department of Health and Human Services, Administration for Child and Families by Child Trends; 2005.

28. McDonald S, Erickson LD, Kirkpatrick Johnson M, Elder J, G H. Informal Mentoring and Young Adult Employment. Social Science Research. 2007; 36(4):1328-1347. [PubMed: 19050736]

29. Hartung P, Porfeli EJ, Vondracek FW. Child vocational development: A review and reconsideration. Journal of Vocationa Behavior. 2005; 66:385-419.

30. Gerhardt CA, Vannatta K, Valerius KS, Correll J, Noll RB. Social and romantic outcomes in emerging adulthood among survivors of childhood cancer. J Adolesc Health. 2007 May; 40(5): 462, e469-e415. [PubMed: 17448406]

31. Jacobson AM, Hauser ST, Cole C, et al. Social relationships among young adults with insulindependent diabetes mellitus: ten-year follow-up of an onset cohort. Diabet Med. 1997 Jan; 14(1): 73-79. [PubMed: 9017357]

32. Thompson AL, Marsland AL, Marshal MP, Tersak JM. Romantic relationships of emerging adult survivors of childhood cancer. Psychooncology. 2009 Jul; 18(7):767-774. [PubMed: 19061200]

33. Shandra CL, Hogan DP. School-to-work program participation and post-high school employment of young adults with disabilities. Journal of Vocational Rehabilitation. 2008; 29:117-130. 
34. Cartwright JD. Provision of educationally related services for children and adolescents with chronic diseases and disabling conditions. Pediatrics. 2007 Jun; 119(6):1218-1223. [PubMed: 17545394]

35. American Academy of Pediatrics. Committee on Children with Disabilities and Committee on School Health: Children with health impairments in schools. Pediatrics. 1990 Oct; 86(4):636-638. [PubMed: 2216634]

36. Wittenburg DC, Golden T, Fishman M. Transition options for youth with disabilities: An overview of the programs and policies affect the transition from school. Journal of Vocational Rehabilitation. 2002; 17(3):195-206.

37. DuPaul, GJ.; Power, TJ.; Shapiro, ES. Schools and Integration/Reintegration into Schools. In: Roberts, MC.; Steele, RG., editors. Handbook of Pediatric Psychology. New York: The Guilford Press; 2009. p. 689-702.

38. Madan-Swain, A.; Katz, ER.; LaGory, J. School and School Reintegration After a Serious Illness or Injury. In: Brown, RT., editor. Handbook of Pediatric Psychology in School Settings. London: LEA; 2004. p. 637-656.

39. La Greca AM, Bearman KJ, Moore H. Peer relations of youth with pediatric conditions and health risks: promoting social support and healthy lifestyles. J Dev Behav Pediatr. 2002 Aug; 23(4):271280. [PubMed: 12177575]

40. Noll RB, Kiska R, Reiter-Purtill J, Gerhardt CA, Vannatta K. A controlled, longitudinal study of the social functioning of youth with sickle cell disease. Pediatrics. Jun; 125(6):e1453-e1459. [PubMed: 20498169] 


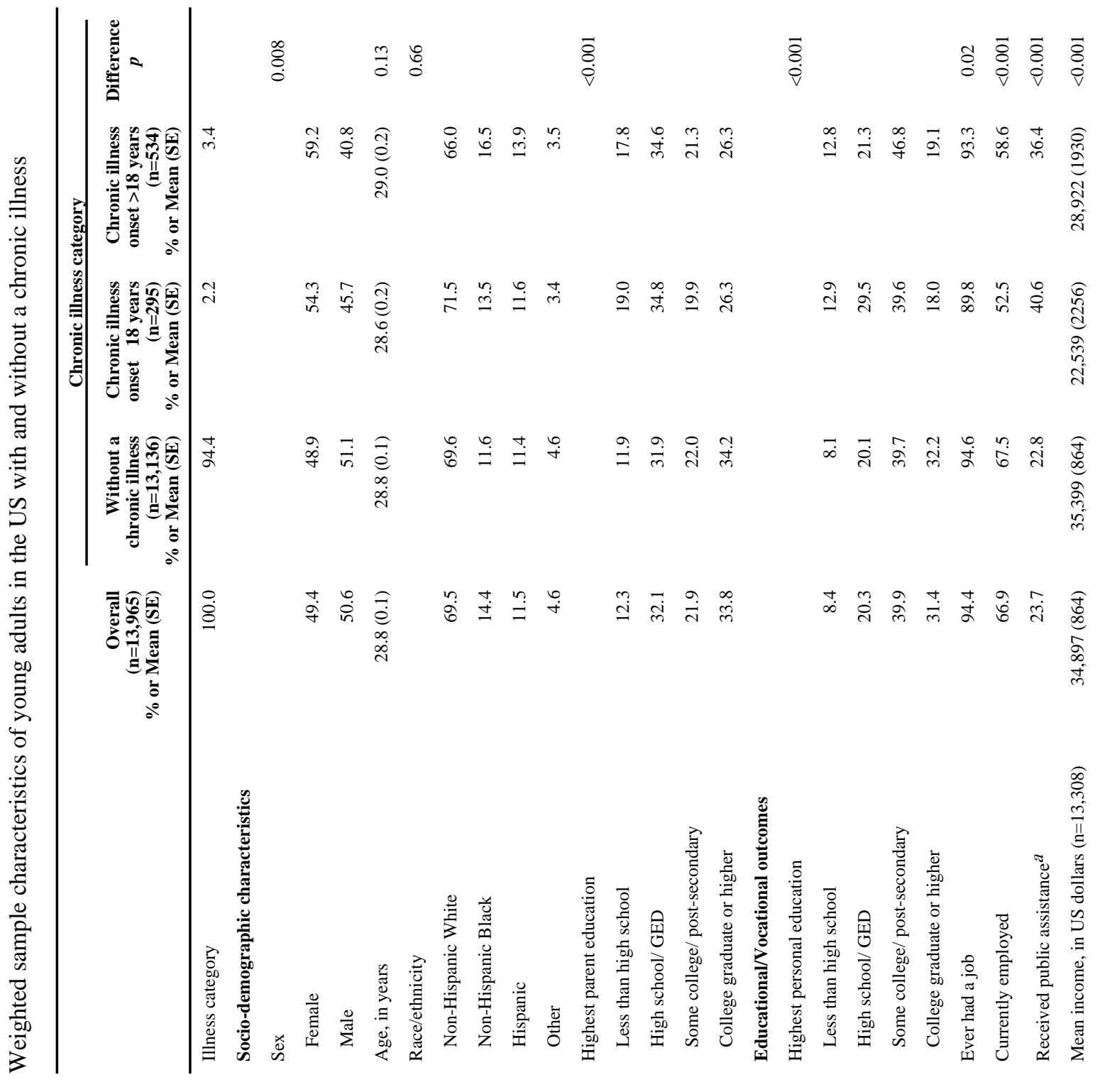




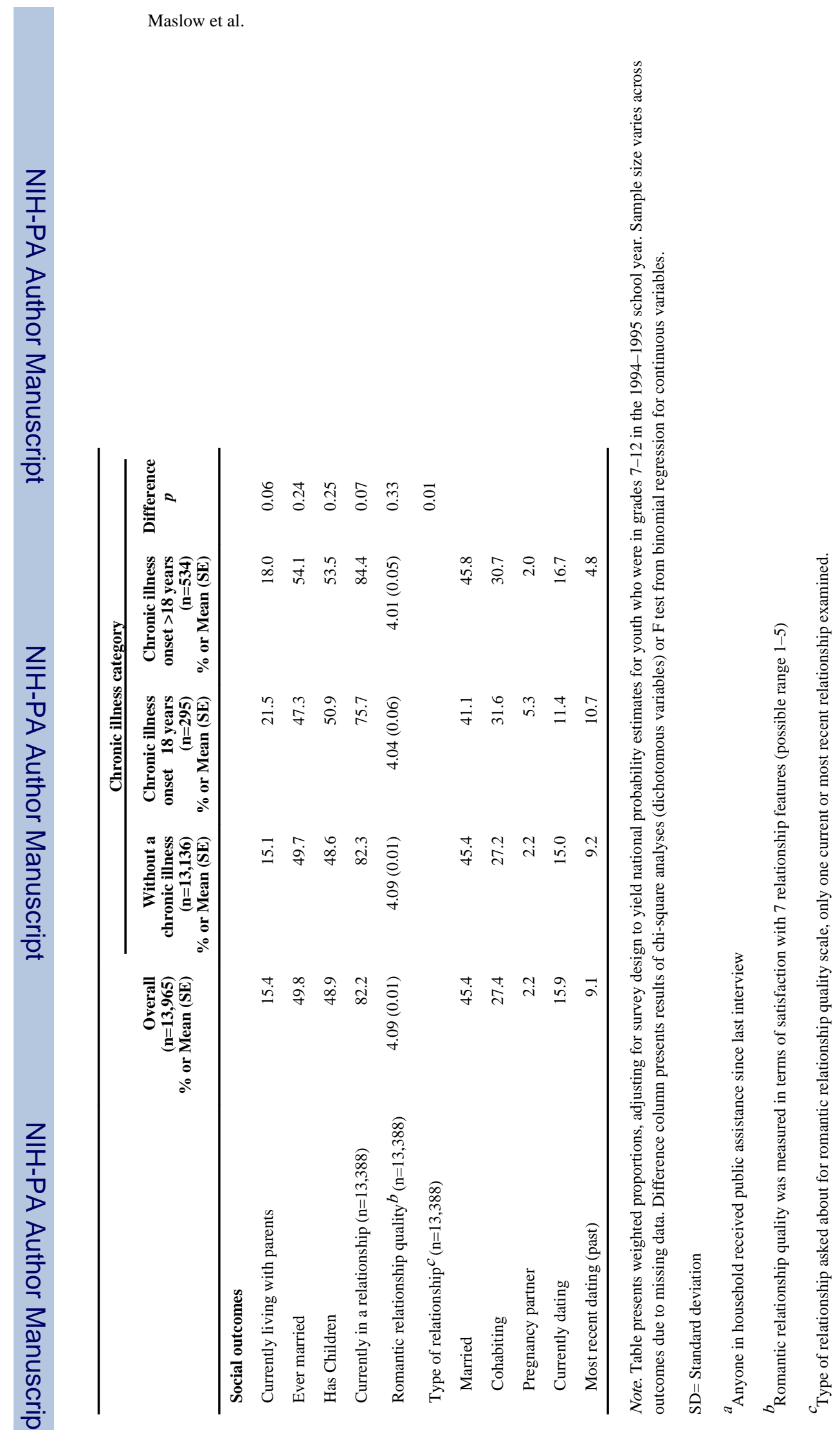

J Adolesc Health. Author manuscript; available in PMC 2012 August 08. 
Table 2

Adjusted odds ratios (OR) from logistic regression models of educational, vocational, and social outcomes among young adults with a chronic illness compared to referent of group without chronic illness.

\begin{tabular}{|c|c|c|c|c|}
\hline & \multicolumn{2}{|c|}{$\begin{array}{l}\text { Chronic illness } \\
\text { onset } \leq 18 \text { years }\end{array}$} & \multicolumn{2}{|c|}{$\begin{array}{l}\text { Chronic illness } \\
\text { onset }>18 \text { years }\end{array}$} \\
\hline & OR & $(95 \% \mathrm{CI})$ & OR & $(95 \% \mathrm{CI})$ \\
\hline \multicolumn{5}{|c|}{ Educational/ vocational outcomes } \\
\hline College Graduate & 0.49 & $(0.31,0.78)^{* *}$ & 0.60 & $(0.38,0.72)^{* *}$ \\
\hline Ever had a job & 0.53 & $(0.29,0.97)^{*}$ & 0.85 & $(0.55,1.30)$ \\
\hline Currently employed & 0.56 & $(0.39,0.80)^{* *}$ & 0.72 & $(0.56,0.93)^{* *}$ \\
\hline Received public assistance ${ }^{a}$ & 2.13 & $(1.39,3.25)^{* *}$ & 1.72 & $(1.33,2.26)^{* *}$ \\
\hline \multicolumn{5}{|l|}{ Social outcomes } \\
\hline Currently living parents & 1.49 & $(0.94,2.33)$ & 1.23 & $(0.92,1.63)$ \\
\hline Ever married & 0.89 & $(0.65,1.24)$ & 1.11 & $(0.86,1.40)$ \\
\hline Has Biological Children & 0.99 & $(0.70,1.42)$ & 1.01 & $(0.80,1.28)$ \\
\hline
\end{tabular}

Note. Table presents results of multivariate logistic regression models comparing outcomes between young adults with a chronic illness to those without a chronic illness (reference category) controlling for sex, age, race/ethnicity, and highest parental education.

$\mathrm{OR}=$ Odds ratio; $\mathrm{CI}=$ Confidence interval

${ }^{a}$ Anyone in household received public assistance since last interview.

* $p<0.05$;

*** $p<0.01$ 


\section{Table 3}

Beta coefficients from linear regression models examining the associations between chronic illness and mean income and romantic relationship quality in young adulthood.

\begin{tabular}{|c|c|c|c|c|}
\hline & \multicolumn{2}{|c|}{$\begin{array}{c}\text { Chronic illness } \\
\text { onset } \leq 8 \text { years } a\end{array}$} & \multicolumn{2}{|c|}{$\begin{array}{c}\text { Chronic illness } \\
\text { onset }>18 \text { years } a\end{array}$} \\
\hline & $\mathbf{b}$ & $(95 \% \mathrm{CI})$ & $\mathbf{b}$ & $(95 \% \mathrm{CI})$ \\
\hline \multicolumn{5}{|l|}{ Educational/ vocational outcomes } \\
\hline Mean income, in US dollars & -5157 & $(-7977,-2336)^{* *}$ & -2271 & $(-6189,1647)$ \\
\hline \multicolumn{5}{|l|}{ Social outcomes } \\
\hline Romantic relationship quality $b$ & -0.01 & $(-0.12,0.11)$ & -0.77 & $(-0.18,0.02)$ \\
\hline
\end{tabular}

Note. Table present results of linear regression analyses controlling for sex, age, race/ethnicity, and highest parental education.

Income model controlled for personal educational attainment, full-time work, and student status.

Model for romantic relationship quality also includes relationship type and whether or not current.

${ }^{a}$ Referent group is the group with No Chronic Illness.

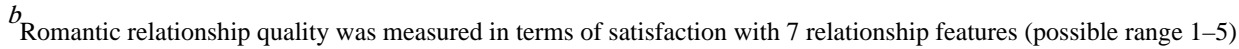

* $p<0.05$;

*** $p<01$ 